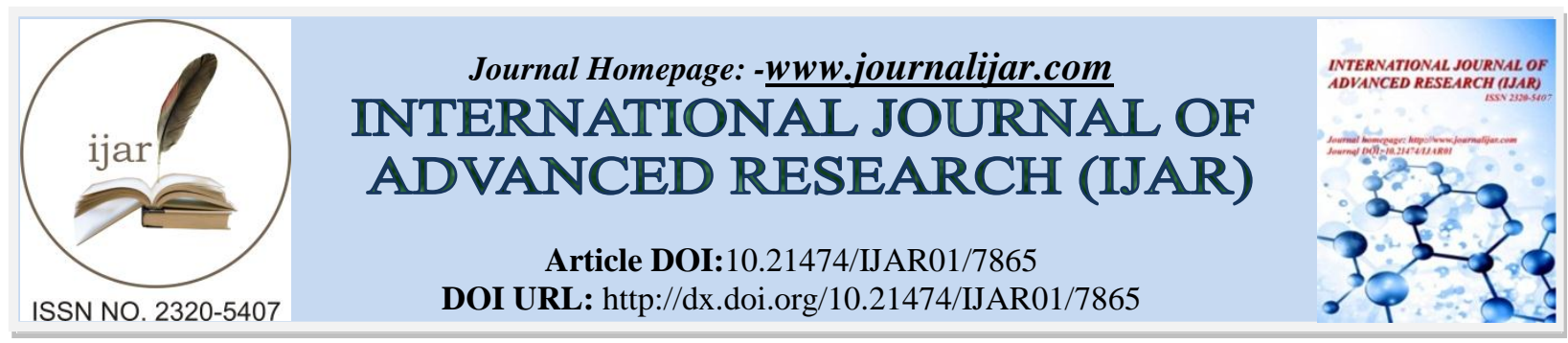

RESEARCH ARTICLE

\title{
HIP ARTHROSCOPY IN MANAGEMENT OF TRAUMATIC AND NON-TRAUMATIC HIP PATHOLOHY.
}

Bakr H.M, Shalaby M.S, Idrees K and Said H.G.

Orthopaedic Surgery Department, Zagazig University Hospitals, Egypt.

\section{Manuscript Info}

\section{Manuscript History}

Received: 9 August 2018

Final Accepted: 11 September 2018

Published: October 2018

Keywords:-

hip arthroscopy, hip pain, femoroacetabular impingement, loose bodies of the hip..

\section{Abstract}

Study Design: prospective non-randomized clinical study.

Background Context:Diagnosis and treatment of intra-articular hip problems in young patients present a challenge. Historically, there have been limited diagnostic and treatment options available for diseases that affect the cartilage, bone or synovium in the young hip joint.Labral tears, degenerative disease, articular injures, osteonecrosis, synovial abnormalities, ligamentumteres rupture, femoroacetular impingement, instability and septic hip are some of the conditions that could now be treated by hip arthroscopy.

Objective:This study will evaluate the effectiveness of hip arthroscopy in diagnosis and treatment of variable hip pathology such as: Labral tears, degenerative disease, articular injures, osteonecrosis, synovial abnormalities, ligamentumteres rupture, femoroacetular impingement.

Patients And Methods: Thirty painful hips undergone hip arthroscopy with minimum 6 months follow up. 28 cases of femoroacetabular impingement (FAI) and two cases of post-traumatic loose body removal.9 cases of femoroacetabular impingement were cam impingement, 7 cases were pincer impingement and 12 cases were mixed impingement. Among our 28 cases of FAI we have found labral pathology in 20 cases, 9 cases of labral pathology managed by labral repair by anchor sutures and rest were managed by debridment. We used modified harris hip score (mHHS) and Non-arthritic hip score (NAHS) to evaluate our results.

Results: A significant improvement was detectedin post-operative hip pain in all cases. Post-operative range of motion was improved.

Conclusion: Hip arthroscopy is a reliable technique to treat traumatic and non-traumatic hip pathology.

Copy Right, IJAR, 2018,. All rights reserved.

\section{Introduction:-}

Diagnosis and treatment of intra-articular hip problems in young patients present a challenge. Historically, there have been limited diagnostic and treatment options available for diseases that affect the cartilage, bone or synovium in the young hip joint. ${ }^{(1)}$

Hip arthroscopy has improved in terms of both technique and technology. Labral tears, degenerative disease, articular injures, osteonecrosis, synovial abnormalities, ligamentumteres rupture, femoroacetular impingement, 
instability, septic hip and adhesive capulitis are some of the conditions that could now be treated by hip arthroscopy. (1)

The hip joint has both a central (intra-articular) and a peripheral compartments. Most of hip pathology is found within the intra-articular region; therefore distraction is necessary to achieve arthroscopic access. The patient can be placed supine or in the lateral decubitus on traction table for the procedure. Both techniques are equally effective; therefore, the choice simply depends on surgeon`s preference. ${ }^{(2)}$

The procedure commonly involves five portals under image intensifier: direct anterior, anterior paratrochanteric or anterolateral, proximal trochanteric, superior paratrochanteric or posterolateral and direct posterior. ${ }^{(3)}$

Contraindications to hip arthroscopy include open wounds; systemic disease; conditions that makes joint entry difficult, such as marked capsular restriction, arthrofibrosis, or ankylosis; poor bone quality that is unable to withstand traction forces. A relative contraindication may not be strong enough to access the joint. ${ }^{(4)}$

The success of the hip arthroscopy often depends on a proper post-operative rehabilitation program. ${ }^{(4)}$

\section{Patients and methods:-}

This prospective study was conducted on thirty patients in orthopaedic department in Asiut University hospital and Zagazig University hospital between 2012 and 2016. All patients proved clinically and radiologically to have a hip problem which was either posttraumatic such as: loose bodies, or atraumatic such as: femoroacetabular impingement of the hip. Hip arthroscopy was done for all thirty patients.

\section{Inclusion criteria:}

Age $>16$ years.

1. Patients with hip pain following trauma such as: hip dislocation, acetabular fracture and femoral head fractures.

2. Patients with persistent hip pain following trauma to the hip without evident fractures such as:labral tears of hip.

3. Patients with persistent hip pain without history of trauma as in cases of femoroacetabular impingement of the hip.

\section{Exclusion criteria:}

1. Severe osteoarthritic patients.

2. Sever lower limb deformity.

3. Septic arthritis of the hip.

\section{Age}

limits in this study was between 17 and 39 years with a mean of 27.1 years (SD \pm 7.2$)$, weight range was $60-103$ $\mathrm{Kg}$ with mean of $79.6 \mathrm{Kg}(\mathrm{SD} \pm 10.5)$.

Pre-operative evaluation was conducted via thorough medical history taking and any known medical conditions were documented.

Patients were evaluated for hip pain according to (mHHS) and NAHS.

Clinical examination was done to assess hip ROM, impingement sign and to assess nearby regions like spine and knee.

Radiological pre-operative assessment was done via plain radiographs, CT and MRI.

$\mathbf{X}$-rays were evaluated for the presence of osseous bump at the head neck junction, pistol grip deformity,

osacetabulai, acetabular overcoverage and acetabular retroversion, cross over sign, ischial spine sign, extrusion index and measuerement of alpha angle.

CT was mainly done to assess the cases of posttraumatic loose bodies.

MRA is done to evaluate the presence and the site of labral tears. 


\section{Surgical technique:}

1. To approach the central compartment: Under general anesthesiaand on the fracture table with wide perineal post under traction we made the anterolateral portal to get an access to the central compartment.

2. To approach the peripheral compartment: we made the proximal anterolateral portal with the hip flexed and the standard anterolateral portal.
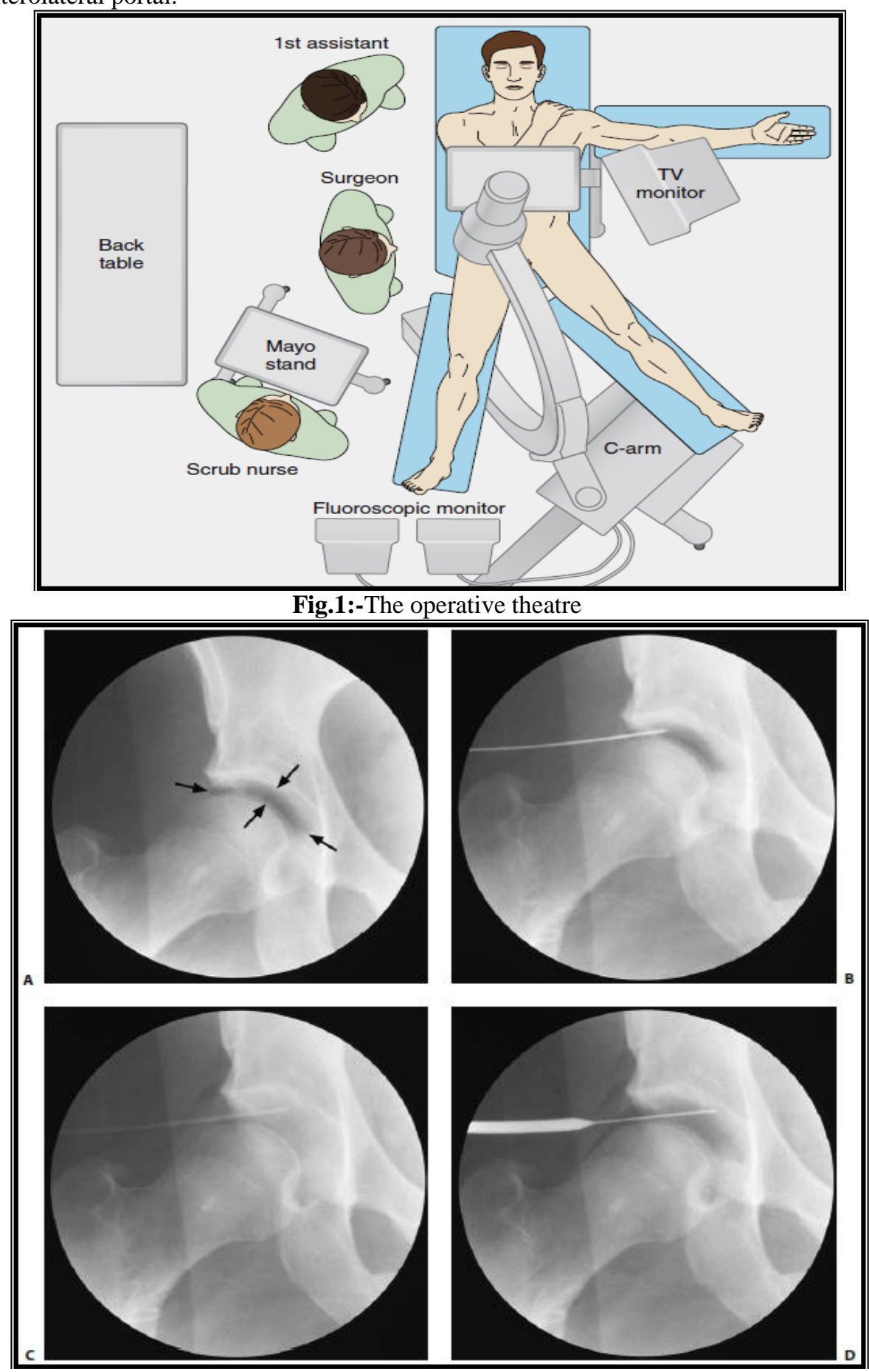

Fig.2:-the anterolateral portal for the central compartment under fluoroscopy 


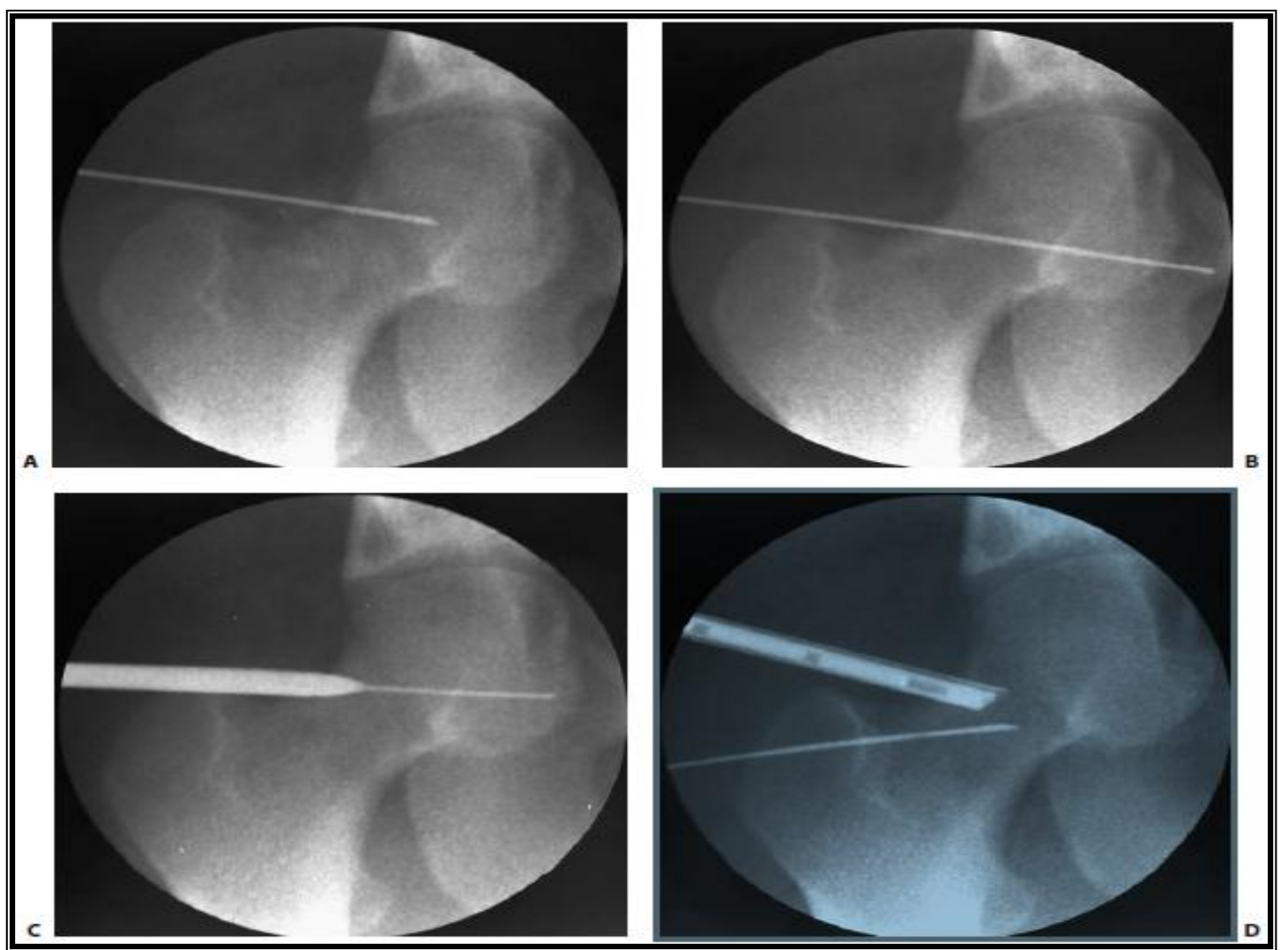

Fig .3:-Portals of the peripheral compartment under fluoroscopy.

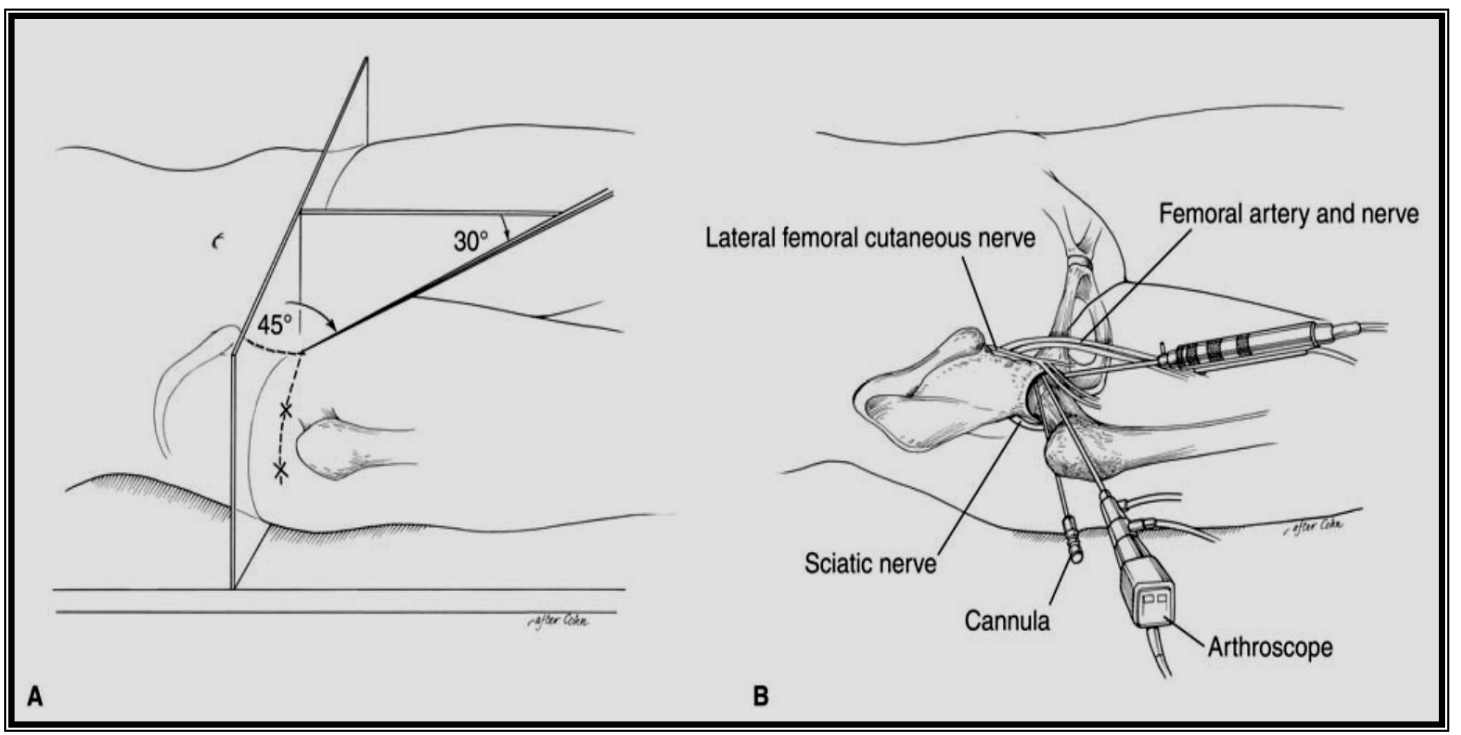

(A) The site of the anterior portal coincides with the intersection of a sagittal line drawn distally from the anteriorsuperior iliac spine and a transverse line across the superior margin of the greater trochanter. The direction of this portal courses approximately $45^{\circ}$ cephalad and approximately $30^{\circ}$ toward the midline. The anterolateral and posterolateral portals (x) are positioned directly over the superior aspect of the trochanter at its anterior and posterior borders. (B) Relationship of the major neurovascular structures to the three standard portals. The femoral artery and nerve lie well medial to the anterior portal. The sciatic nerve lies posterior to the posterolateral portal. Small branches of the lateral femoral cutaneous nerve lie close to the anterior portal. Injury to these is avoided by using 
proper technique in portal placement. The anterolateral portal is established first because it lies most centrally in the safe zone for arthroscopy. ${ }^{(5)}$
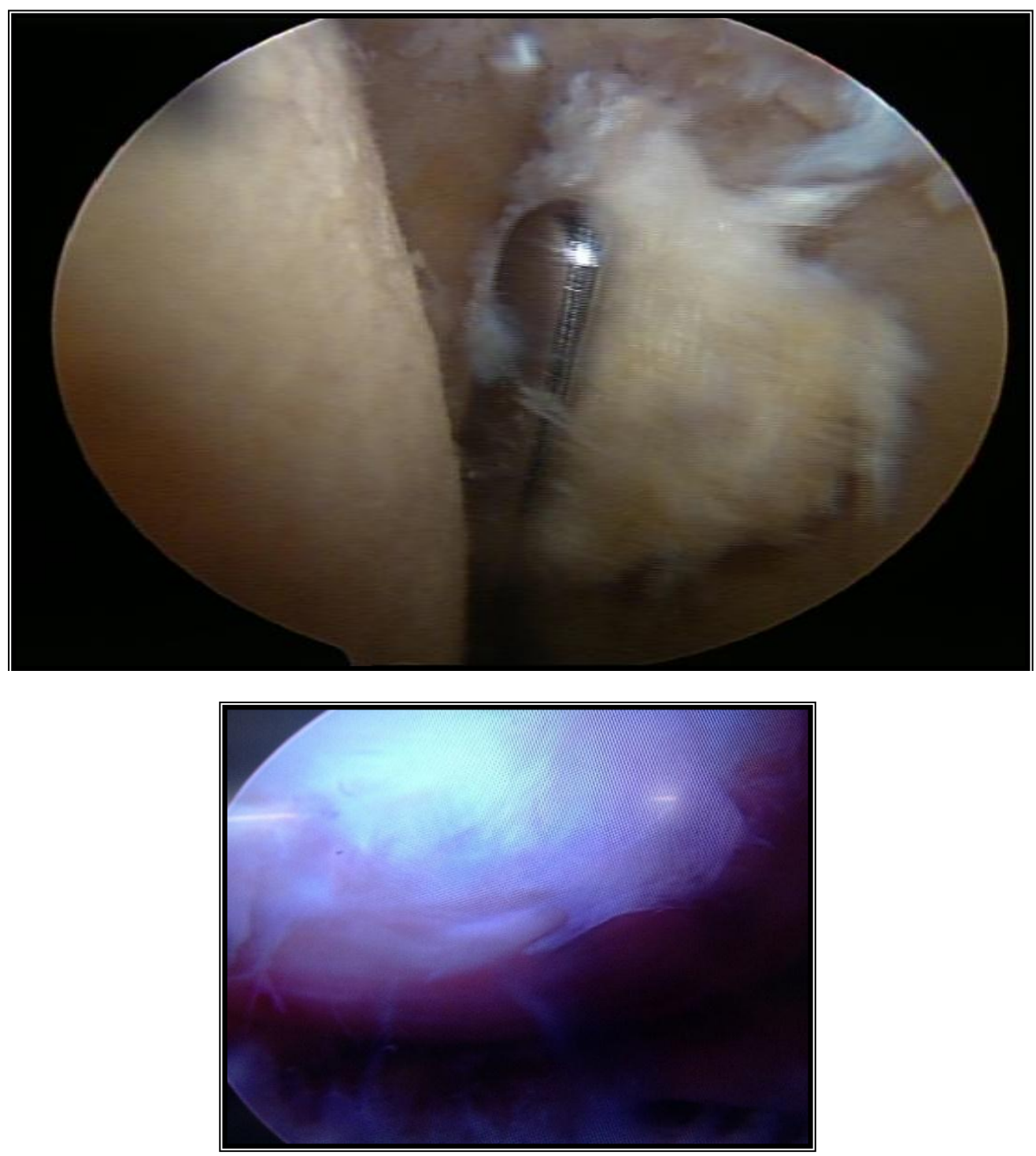

Fig .5:-Arthroscopic loose body excision.

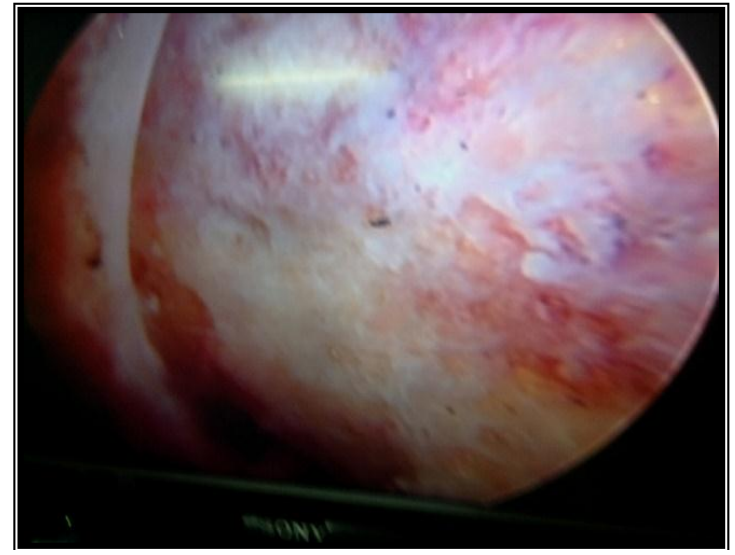

Fig.6:-Cam lesion 


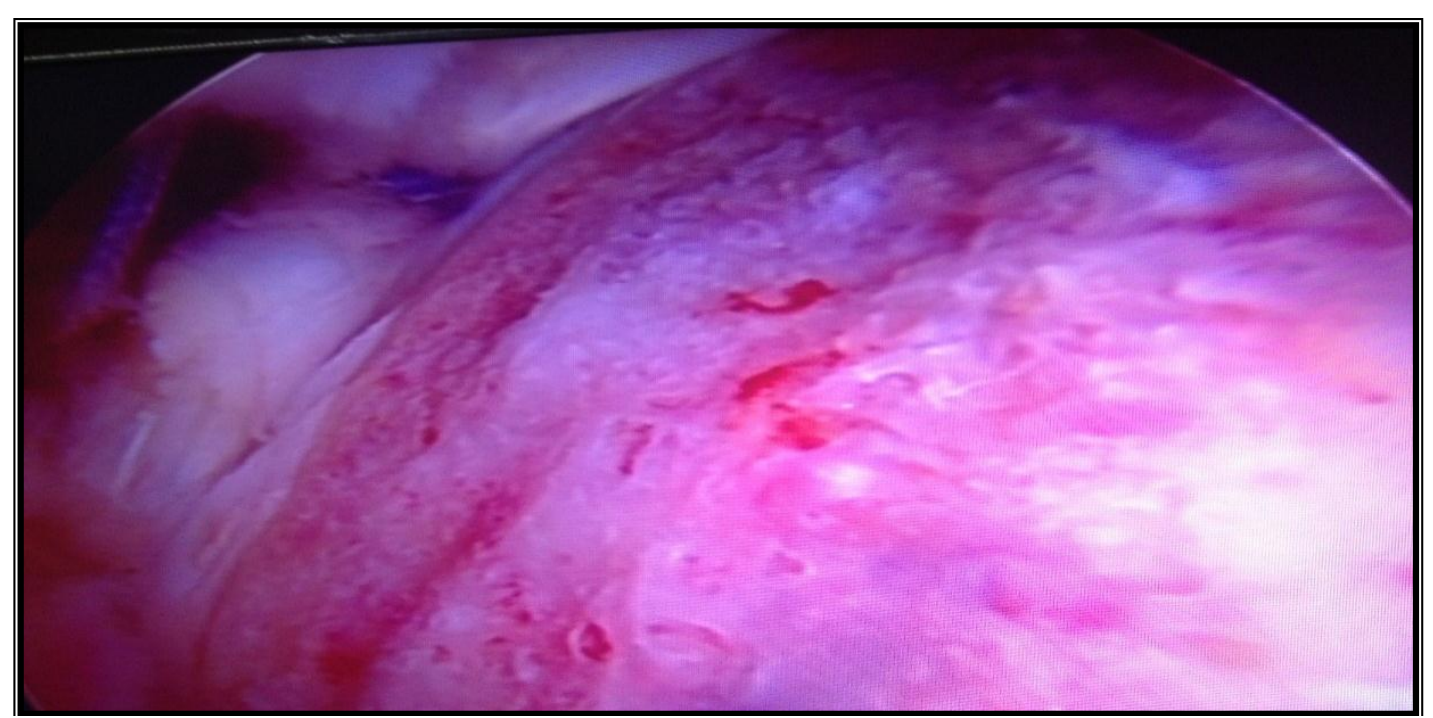

Fig.7:-Cam lesion osteoplastyand labral repair by anchors.

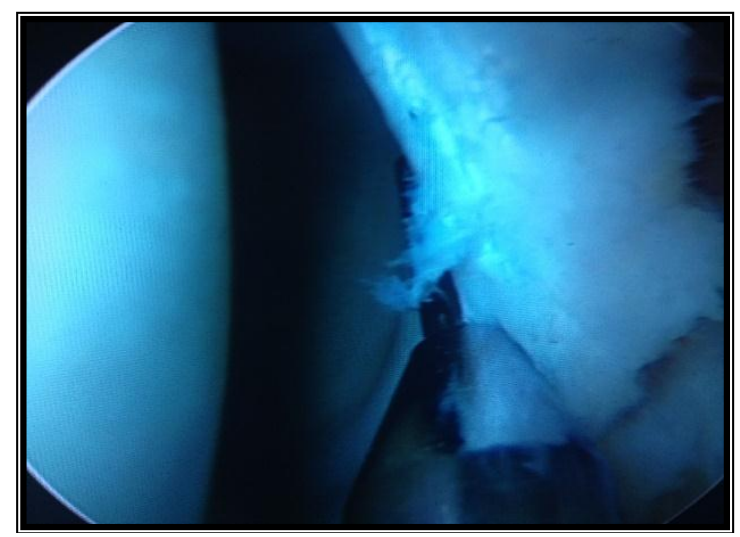

Fig.8:-Labraldebridment

Follow up:

Visits were conducted 2 weeks, 3 months, 6 months and one year and every one year after. At each visit, patients were assessed both clinically using mHHS and NAHS.

\section{Statistical analysis:}

The collected data were computerized and statistically analyzed using SPSS program (Statistical Package for Social Science) version 18.0.Qualitative data were represented as frequencies and relative percentages. Macnemmar test was used to calculate difference between qualitative variables in different times.Quantitative data were expressed as mean \pm SD (Standard deviation).

Mann Whitney test was used to calculate difference between quantitative variables in 2 groupsin not normally distributed data.Paired sample $\mathrm{T}$ test was used to calculate difference between quantitative variables in the same group pre and post therapy in normally distributed data. Paired Willicoxon test was used to calculate difference between quantitative variables in the same group pre and post therapy in not normally distributed data.

The significance Levelfor all above mentioned statistical tests done. the threshold of significance is fixed at 5\% level (P-value)

1. $* \mathrm{P}$ value of $>0.05$ indicates non-significant results.

2. *P value of $<0.05$ indicates significant results.

3. $* \mathrm{P}$ value of $<0.01$ indicates highly significant results.

Percent of change was calculated as follow: $\%$ of change $=(($ post value - pre value $) /$ pre value $) \times 100$. 


\section{Results:-}

\section{Assessment by NAHS}

Regarding overall outcome of all patients in the study, the preoperative score was of a mean value of 51.6 and standard deviation of 16.4. The postoperative score at 6 months was of a mean value of 74.4 and standard deviation of 15.1 , mean improvement was 22.8 points.

The improvement of the NAHS at 6 months postoperatively was statistically highly significant with $\mathrm{P}$ value $<0.001$.

\begin{tabular}{|l|c|c|c|}
\hline & Mean \pm SD & $\begin{array}{c}\text { P value } \\
\text { (paired ttest) }\end{array}$ & Significance \\
\hline Pre NAHS & $51.6 \pm 16.4$ & $<0.001$ & Highly significant \\
\hline 6 Months NAHS & $74.4 \pm 15.1$ & & \\
\hline
\end{tabular}

Table1:-Comparison of preoperative NAHS and 6 months postoperative.

Assessment by mHHs:

Regarding overall outcome of all patients in the study, the preoperative score was of a mean value of 52.6 and standard deviation of 15.5 .

Thepostoperative score at 6 months was of a mean value of 72 and standard deviation of 17.3, mean improvement was 19.4 points.

The improvement of the mHHS at 6 months postoperatively was statistically highly significant with $\mathrm{P}$ value $<0.001$.

\begin{tabular}{|l|c|c|}
\hline & Mean \pm SD & $\begin{array}{c}\text { P value } \\
\text { (Highly significant }\end{array}$ \\
\hline Pre mHHS & $52.6 \pm 15.5$ & $<\mathbf{0 . 0 0 1 * *}$ \\
\hline 6 months HHS & $72.0 \pm 17.3$ & \\
\hline
\end{tabular}

Table 2:-Comparison of preoperative mHHS and 6 months postoperative

\section{Complications:}

Among 30 cases in our study, only one patient showed transient neurapraxia of the femoral nerve, and one patient showed transient neuropraxia of the pudendal nerve. The complication rate in our study is $6.67 \%$. All cases showed complete recovery on postoperative rehabilitation programs and conservative therapy.

\section{Discussion:-}

In this study, we had a 30 cases were subjected to preliminary systematic diagnostic hip arthroscopy. The arthroscopic findings were as the following:

1. Two cases of neglected post-traumatic loose bodies managed by arthroscopic removal.

2. 28 cases of femoroacetabular impingement syndrome, which are further subclassified into 9 cases of isolated Cam impingement managed by cam osteoplasty, 7 cases of isolated pincer impingement managed by acetabular rim trimming and 12 cases of mixed impingement.

Among the 28 cases of FAI, labral pathology was found in 20 cases which was managed by labraldebridment in 11 cases and repair in 9 cases.

All patients were assessed with mHHS and NAHS preoperatively and postoperatively at 6,12 and 24 months, the minimum allowed follow up period was 6 months, the sixth month follow up score was that which was recorded for each patient in the results analysis, compared to preoperative scores.

Regarding overall outcome of patients in the study, Mean NAHS improved from 51.6 preoperatively to 74.4 postoperatively (mean improvement $=22.8$ ), and mean mHHS scores improved from 52.6 preoperatively to 72 postoperatively (mean improvement $=19.4$ ). Regarding the two cases of post-traumatic loose body removal, the outcome of the $1^{\text {st }}$ patient was improvement in mHHS from 52 preoperatively to 55 postoperatively (improved 3 points) and in NAHS from 60 preoperatively to 64 postoperatively (improved 4 points). The $2^{\text {nd }}$ patient is improved in mHHS from 50 preoperatively to 85 postoperatively (improved 35 points) and in NAHS improved from 52 preoperatively to 78 postoperatively (improved 26 points). That was supported by the results of (Byrd et al., 2010) in a prospective study on seven cases of loose bodies among a cohort of 50 patients (52 hips) represent the substance of 
the study. They reported that the mHHS improved by a median score of 39 points, and they stated that removal of symptomatic loose bodies was recognized to be one of the most gratifying of all arthroscopic procedures. ${ }^{(6)}$

Chernchujit et al., (2009) also reported on seven cases of retained loose fragments after hip reduction that were treated by arthroscopic loose body removal. The mean follow up was 15.7 months. The average postoperative mHHS was 89.8 and no complications were reported. ${ }^{(7)}$

In our study, 28 patients underwent arthroscopic management of femoroacetabular impingement (FAI), 9 patients underwent femoral osteoplasty only for cam impingement, 7 patients underwent rim trimming only for pincer impingement, and 12 patients underwent both procedures for mixed-type impingement.

For overall outcome of the FAI cases, mean NAHS improved from 51.7 preoperatively to 74.5 postoperatively (mean improvement $=22.8$ ), and mean mHHS scores improved from 52.7 preoperatively to 72.1 postoperatively (mean improvement $=19.4$ ). That is supported by the results of (Philippon et al., 2009) reported two year outcomes of 112 patients who underwent arthroscopic surgery of the hip for femoroacetabular impingement. 23 patients underwent osteoplasty only for cam impingement, 3 underwent rim trimming only for pincer impingement, and 86 underwent both procedures for mixed-type impingement. Mean follow-up was 2.3 years. Mean modified Harris hip score (HHS) improved from 58 to 84 (mean difference $=24) .{ }^{(8)}$

In 2009, Brunner et al, reported average 2.4-year follow-up on 53 FAI cases. The mean NAHS improved from 54.4 to 85.7 . Overall, 50 of the 53 (94\%) were "very highly satisfied" with the surgical results. ${ }^{(9)}$

In 2009, Byrd and Jones, reported on 207 FAI hips treated arthroscopically. They reported a 20-point mean increase in mHHS and a $0.5 \%$ conversion rate to THA at minimum 1-year follow-up (mean 16 months). ${ }^{(10)}$

Among the 28 cases of FAI, we found 20 cases of labral pathology, 11 cases underwent labraldebridment and 9 cases underwent labral repair by anchor sutures. We have found no significant statistical difference in the mean improvement in (mHHS, NAHS) between the two methods.

The mean value for preoperative mHHs for the 11 cases of labraldebridment was 53 and standard deviation of 13.7, the mean value for postoperative mHHS was 76.2 and standard deviation of 10.9, mean improvement was 23.2. While the mean value for preoperative mHHs for the 9 cases of labral repair was 53 and standard deviation of 22.5, the mean value for postoperative mHHS was 72.1 and standard deviation of 15.1, mean improvement was 19.1.

The $\mathrm{p}$ value for this comparison between the mean value of improvement for each technique was 0.59 , which means that there no statistically significant difference in results between both techniques.

The mean value for preoperative NAHS for the 11 cases of labraldebridment was 50.3 and standard deviation of 17.2, the mean value for postoperative NAHS was 76.5 and standard deviation of 11.3 , mean improvement was 26.3. While the mean value for preoperative NAHS for the 9 cases of labral repair was 55.3 and standard deviation of 19.2, the mean value for postoperative mHHS was 73.7 and standard deviation of 10 , mean improvement was 17.3.

These results are not supported by the results conducted by (Larson et al., 2012) whoconducted comparative study of arthroscopic labral debridement (44 hips) and labralrefixation (50 hips), The mHHS ( $\mathrm{P}=.001)$, SF-12 ( $\mathrm{P}=.041)$, and VAS pain scores $(\mathrm{P}=.004)$ were all significantly better for the refixation group compared with the debridement group at the most recent follow-up. At a mean 3.5 years' follow-up, good to excellent results were noted in $68 \%$ of the focal excision/debridement group and $92 \%$ of the refixation group $(\mathrm{P}=.004){ }^{(11)}$

Schilders el al, (2011) reported, in a study done upon 156 hips after exclusion of hips with degenerative disorders at a mean follow up of 2.44 years, that labral repair group improved from 60.2 preoperatively to 93.6 postoperatively and labral resection group improved from 62.8 preoperatively to 88.8 postoperatively, the mean mHHS in labral repair group was 7.3 greater than labral resection group. ${ }^{(\mathbf{1 2})}$

Our results in supported by the results conducted by (Santori and Villar, 2000) who reported a satisfaction rate of $67 \%$ among 58 cases with a mean of 3.5 years' follow-up after labraldebridment. ${ }^{(13)=(61)}$ 
Among 30 cases in our study, only one patient showed transient neurapraxia of the femoral nerve and only one patient showed transient neuropraxia of the pudendal nerve with percentage of $6.67 \%$. All cases showed complete recovery on postoperative rehabilitation programs and conservative therapy.

We suggest that neuronal manifestations was attributed to long traction time, there was no recurrence of this complication after a protocol of intermittent traction and proper preoperative positioning in subsequent cases.

Several authors have described complications which are probably due to traction. Glick ${ }^{(14)}$ found eight cases of neurapraxia in 60 hip arthroscopies. The pudendal nerve was affected in four and the sciatic nerve in the others, but all recovered fully. In 19 consecutive hip arthroscopiesFunke and Munzinger ${ }^{(15)}$ reported one case of neurapraxia of the pudendal nerve, which recovered completely within three weeks. Byrd ${ }^{(16)}$ had two cases of palsy of the pudendal nerve in 20 consecutive hip arthroscopies. These also resolved in a week or so. In a series of 24 arthroscopies carried out in children and young adults, Schindler $\boldsymbol{e t} \boldsymbol{a l}^{(17)}$ reported that one man and one woman developed transient dysaesthesia of the pudendal nerve. It is possible that this structure may be affected by direct pressure from a perineal or inner thigh post. Traction and excessive extension of the hip may damage the femoral nerve, and excess flexion of the hip may injure the sciatic nerve. ${ }^{(18)}$

Brumback et al, believed that the frequency of palsy of the pudendal nerve was associated more with the magnitude of intraoperative traction than with the duration of the procedure. ${ }^{(19)}$

Sampson, (2001) has reviewed complications in 530 cases of hip arthroscopy and found a total complication rate of $5.5 \%$. Of these, $0.5 \%$ were considered permanent, and $5 \%$ were transient. The most common complications were transient neuropraxias of the peroneal, femoral, sciatic, lateral femoral cutaneous and pudendal nerves secondary to traction. These complications typically resolved in 2 to 3 days. ${ }^{(20)}$

\section{Conclusion:-}

Hip arthroscopy is an effective procedure for treatment of multiple hip problems like FAI, loose body removal and labral pathology.

FAI is classified into Cam type which is treated arthroscopically by osteoplasty, while Pincer type is treated by rim trimming.

Labral pathology can be treated arthroscopically by labraldebridment using the shaver or labral repair using anchor sutures.

\section{References:-}

1. Shetty, V. D, andVillar, R. N. (2007): Hip arthroscopy: current concepts and review of literature.British journal of sports medicine; 41(2), 64-68.

2. Byrd, J. T. (2005): Overview and History of Hip Arthroscopy. Operative Hip Arthroscopy, (pp. 1-6). Springer New York.

3. Michael B, Gerhardt, K.L, Morteza M and Anil S. (2011): Arthroscopic and open anatomy of the hip, Techniques in Hip Arthroscopy and Joint Preservation Surgery;Elsevier. pp. 9-22.

4. Shu, B., andSafran, M. R. (2011): Hip instability: anatomic and clinical considerations of traumatic and atraumatic instability. Clinics in sports medicine; 30, 349-367.

5. Byrd JWT. (2005): Portal anatomy in: Byrd $\mathrm{J}$ W $\mathrm{T}$, editor. Operative hip arthroscopy.2 nd edition. NewYork:Springer; p.100-110.

6. Byrd JW and JonesKS (2010): Prospective analysis of hip arthroscopy with 10 yearfollowup. ClinOrthopRelat Res 468:741-746.

7. Chernchujit B, et al., (2009): Arthroscopic loose body removal after hip fracture dislocation: experience in 7 cases. J Med Assoc Thai.

8. Philippon MJ, Briggs KK, Yen YM, et al., (2009): Outcomes following hip arthroscopy for femoroacetabular impingement with associated chondrolabral dysfunction: minimum two-year follow-up. J Bone Joint Surg Br; 91:16-23.

9. Brunner A, Horisberger $M$ and Herzog R.F.(2009): Sports and recreation activity of patients with femoroacetabular impingement before and after arthroscopic osteoplasty. Am J Sports Med 37:917 922. 
10. Byrd JW and Jones K.S. (2009): Arthroscopic femoroplasty in the management of cam-type femoroacetabular impingement. ClinOrthopRelat Res 467:739-746.

11. Larson CM and Giveans M.R. (2009): arthroscopic debridment versus refixation of acetabular labrum associated with femoroacetabular impingement. Arthroscopy 25(4), 369-376.

12. Schilders E, Dimitrakopoulou A, Bismil Q, Marchant $\mathbf{P}$ and Cooke $\mathbf{C}$ (2011): arthroscopic treatment of labral tears in femoroacetabular impingement: a comparative study of refixation and resection with a minimum two-years follow up. J Bone Joint Surg Br 93(8), 1027-1032.

13. Santori N andVillar RN (2000): Acetabular labral tears: Result of arthroscopic partial limbectomy. Arthroscopy; 16:11-15.

14. Glick J.M. (1991): Hip arthroscopy. In: McGinty JB, ed. Arthroscopy.New York: Raven Press: 663-76.

15. Funke EL andMunzingerU.(1996): Complications in hip arthroscopy. Arthroscopy; 12:156-9.

16. Byrd JW (1994): Hip arthroscopy utilizing the supine position. Arthroscopy;10:275-280.

17. Schindler A, Lechevallier JJ, RaoNS and Bowen JR (1995): Diagnostic and therapeutic arthroscopy of the hip in children and adolescents: evaluation of results. J PediatrOrthop; 15:317-21.

18. Villar RN (1992): Hip arthroscopy. Butterworth-Heinemann Ltd,Oxford.

19. Brumback R, Ellison TS, Molligan H, et al., (1992): Pudenal nerve palsy complicating intramedullary nailing of the femur. J Bone Joint Surg [Am]; 74-A: 1450-5.

20. Sampson T.G. (2001): Complications of hip arthroscopy. Clin Sports Med; 20(4):831-835. 